\title{
Thermo-mechanical Fatigue of the Nickel-Base Superalloy Nimonic 90
}

\author{
M. Marchionni ${ }^{1, a}$, H. Klingelhöffer ${ }^{2, b}$ H. Kühn²,c, T. Ranucci ${ }^{1, d}, K^{2}$ Matzak $^{2, e}$ \\ ${ }^{1}$ Consiglio Nazionale delle Ricerche - Istituto per l'Energetica e le interfasi (CNR-IENI), \\ Via Roberto Cozzi 53, 20125 Milano, Italy; \\ ${ }^{2}$ Federal Institute for Materials Research and Testing (BAM), \\ Unter den Eichen 87, 12205 Berlin, Germany \\ a marchionni@ieni.cnr.it, ${ }^{b}$ hellmuth.klingelhoeffer@bam.de, \\ c hans-joachim.kuehn@bam.de, ${ }^{\mathrm{d}}$ ranucci@ieni.cnr.it , ${ }^{\mathrm{e}}$ kathrin.matzak@bam.de
}

Keywords: Thermo-mechanical fatigue, TMF, LCF, nickel base superalloy, Nimonic 90

\begin{abstract}
The thermo-mechanical fatigue (TMF) behaviour of the Nimonic 90 Nickel base superalloy has been investigated within two laboratories. In-phase-tests (IP) where the maximum mechanical strain occurs at the maximum temperature $\left(850^{\circ} \mathrm{C}\right)$, and $180^{\circ}$-out-of-phase-tests $\left(180^{\circ}\right.$ OP) where the maximum mechanical strain coincides with the minimum temperature $\left(400^{\circ} \mathrm{C}\right)$ have been applied. All tests were carried out at varying mechanical strain ranges with a constant strain ratio of $R_{\varepsilon}=-1$. A temperature rate of $5 \mathrm{~K} / \mathrm{s}$ was used throughout the whole cycle without any additional cooling system during decreasing temperature. The fatigue life of $180^{\circ} \mathrm{OP}$ tests is longer compared to identical IP tests. The stress / mechanical strain hysteresis loops are completely different and some characteristic values are compared to each other. The fracture surfaces observed show that fatigue crack (or cracks) starts on the external surface and propagates inwards. The fractures of $180^{\circ} \mathrm{OP}$ tests are transgranular showing the presence of fatigue striations, while the fractures of IP tests are mixed transgranular and intergranular with no fatigue striations.
\end{abstract}

\section{Introduction}

Since the seventies, materials subjected to cyclic stresses and temperatures have been studied by isothermal low cycle fatigue testing (LCF) and the results have been produced by considering a reference temperature that corresponds to the maximum value of the thermal cycling. After the introduction of thermo-mechanical fatigue (TMF) as a diagnostic device for the material study [1], the comparison of LCF and TMF testing has determined opposite conclusions. Partly LCF and TMF results were found to be comparable $[2,3]$. Partly it was found that the stress history of a thermomechanical cycle leads to results completely different from those produced by isothermal testing [4, 5,]. The TMF procedure is particularly recommended for those new materials whose high temperature properties are not known. There is clear evidence that the TMF test procedure does represent material loading of hot components in e.g. power stations and aero engines much better than LCF testing.

In order to customise the TMF testing procedure a European project has recently concluded [6] and a Code of Practice (CoP) has produced [7]. The TMF tests were performed on the Nickel base superalloy Nimonic 90 at defined experimental conditions and the results contributed to the definition of the test procedure. The scope of the present work is to extend the comparison of TMF results performed on Ni90 alloy according to the $\mathrm{CoP}$ procedure and to verify the material life in different experimental conditions.

\section{Experimental Testing Technique}

At both laboratories TMF tests were performed on a 100 / $250 \mathrm{KN}$ servo-hydraulic testing machine, a $6 / 17.5 \mathrm{kVA}$ induction furnace and a controller for load, strain and temperature variations according to a programme previously defined. Specimens with cylindrical gauge length and $6 \mathrm{~mm}$ 
diameter were used. Test temperature is controlled by $\mathrm{K}$ type thermocouple spot-welded outside the gauge length in order to avoid the crack initiation at the welding. The temperature profile in the gauge length is optimized and calibrated before a series of experiments. A thermal strain calibration is performed in the temperature range selected before each TMF test. It is obtained by performing a thermal cycle, repeated at least five times, having the same shape of the TMF cycle in order to determine the mean values of the cycles. In practice the total strain is the sum of the mechanical and the thermal strain previously determined. In such way the specimen thermal strain is compensated during all the thermo-mechanical cycle.

\section{Material and Testing Conditions}

The wrought Ni-base superalloy Nimonic 90 with a nominal composition of (wt. \%) Ni 59, Cr 19.5, Co 16.5, Al 1.5, Ti 2.5, Mn 0.3, Si 0.3, C 0.07, B 0.003 and $\mathrm{Zr} 0.006$ was used for TMF tests. The alloy has an equiaxed grain structure with an average grain size of $72 \mu \mathrm{m}$. Bars of $20 \mathrm{~mm}$ diameter were solution heat treated for $8 \mathrm{hrs}$ at $1080^{\circ} \mathrm{C}$, water quenched and then aged for a $5 \mathrm{hrs}$ at $850^{\circ} \mathrm{C}$ to obtain blanks for manufacturing test pieces. The temperature range was from 400 to $850^{\circ} \mathrm{C}$ with triangular wave-form and a temperature rate of $5 \mathrm{~K} / \mathrm{s}$. The mechanical strain cycle was also triangular in phase and $180^{\circ}$ out of phase with temperature cycle.

\section{TMF Results and Discussion}

The TMF results are described in table 1. Fig. 1 shows the cyclic hardening and softening curves of the TMF tests. At OP tests a little hardening is observed in tension and softening is obtained in compression. This can be explained by the influence of temperature where low temperature encourages hardening and high temperature softening. For IP tests the opposite situation can be seen (Fig. 1). This behaviour is similar to that at isothermal LCF tests (Fig. 2) where the same hardening and softening behaviour is found. The curves of both laboratories fit very well.

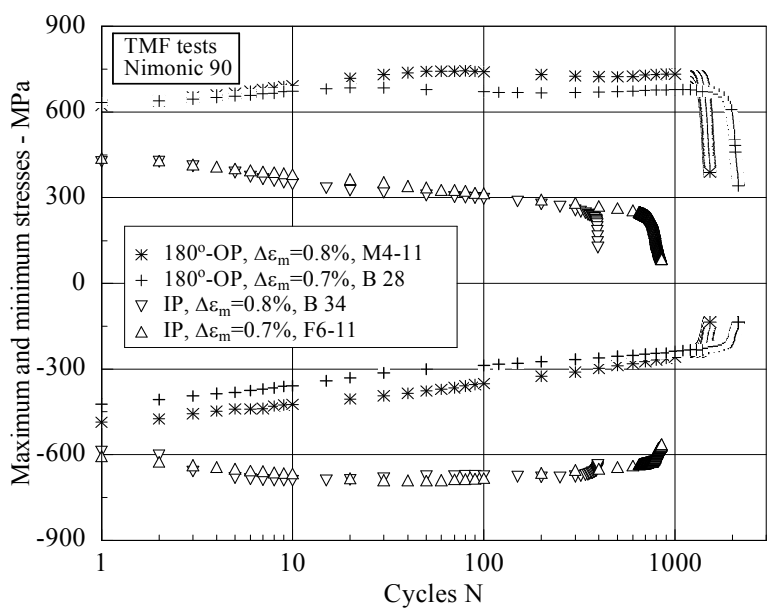

Figure 1: Cyclic hardening and softening curves of the material Nimonic 90 for TMF tests, $400-850^{\circ} \mathrm{C}$

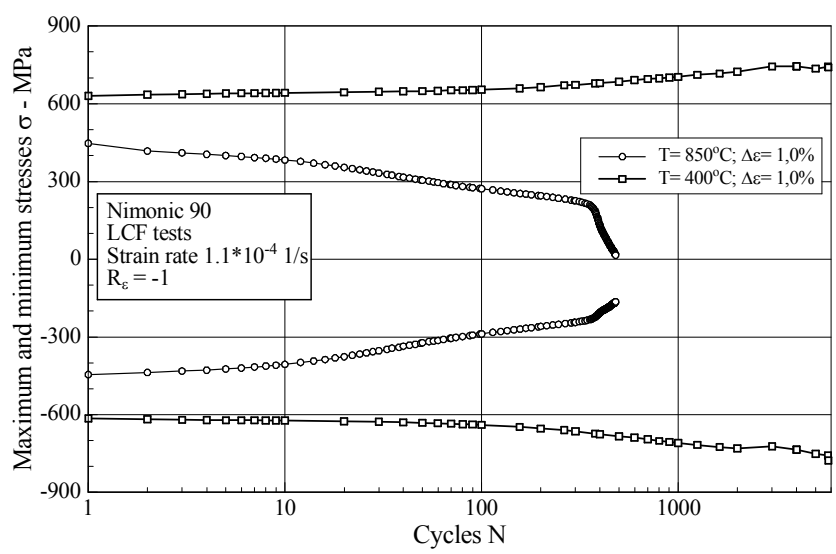

Figure 2: Cyclic hardening and softening curves of Nimonic 90 alloy for LCF tests at 400 and $850^{\circ} \mathrm{C}$

The high stress levels in tension for OP tests are due to the minimum temperature within the TMF cycle while they are low in compression at the maximum temperature. This behaviour is well known as the temperature dependent strength. For IP tests the opposite stress values are found. The shape of hysteresis loops for IP and OP tests are quite different. The OP hysteresis loop has significant higher tensile stresses of an approx. factor of 2-3 compared to the compression stresses. Generally the tensile stresses support crack growth. The IP hysteresis loop shows low tensile and high compression stresses. 


\begin{tabular}{|c|c|c|c|c|c|c|c|c|}
\hline Tested by & Test no & $\begin{array}{c}\text { TMF, LCF } \\
\text { Cycle }\end{array}$ & $\begin{array}{c}\text { Temp, } \\
{\left[{ }^{\circ} \mathrm{C}\right]}\end{array}$ & $\begin{array}{l}\Delta \varepsilon_{\mathrm{m}} \\
{[\%]}\end{array}$ & $\begin{array}{c}\Delta \varepsilon_{\text {in }} \text { at } \mathrm{N} / 2 \\
{[\%]}\end{array}$ & $\begin{array}{c}\sigma_{\max } \text { at } \mathrm{N} / 2 \\
{[\mathrm{MPa}]}\end{array}$ & $\begin{array}{c}\sigma_{\min } \text { at } \mathrm{N} / 2 \\
{[\mathrm{MPa}]}\end{array}$ & $\mathrm{N}_{10}$ \\
\hline BAM & L3-5 & IP & $400-850$ & 0.6 & - & 258 & -631 & 1350 \\
\hline BAM & F6-11 & $\overline{I P}$ & $400-850$ & 0.7 & 0.219 & 271 & -650 & 755 \\
\hline BAM & J4-11 & $\mathrm{IP}$ & $400-850$ & 0.7 & 0.256 & 238 & -621 & 813 \\
\hline BAM & L5-11 & $\mathrm{IP}$ & $400-850$ & 0.7 & 0.229 & 273 & -609 & 944 \\
\hline BAM & F6-21 & $\mathrm{IP}$ & $400-850$ & 0.7 & 0.113 & 272 & -677 & 690 \\
\hline CNR & L5-21 & $\mathrm{IP}$ & $400-850$ & 0.7 & 0.144 & 255 & -644 & 805 \\
\hline CNR & J4-21 & $\mathrm{IP}$ & $400-850$ & 0.7 & 0.138 & 263 & -645 & 805 \\
\hline CNR & B34 & $\mathrm{IP}$ & $400-850$ & 0.8 & 0.23 & 275 & -668 & 396 \\
\hline BAM & L3-3 & $\mathrm{IP}$ & $400-850$ & 1.0 & - & 344 & -777 & 184 \\
\hline CNR & B27 & $\mathrm{IP}$ & $400-850$ & 1.2 & 0.509 & 432 & -795 & 64 \\
\hline CNR & B28 & OP-180 & $400-850$ & 0.7 & 0.19 & 669 & -235 & 1970 \\
\hline CNR & K3-21 & OP-180 & $400-850$ & 0.8 & 0.236 & 753 & -285 & 1530 \\
\hline CNR & G4-21 & OP-180 & $400-850$ & 0.8 & 0.238 & 756 & -293 & 1355 \\
\hline CNR & M4-21 & $\mathrm{OP}-180^{\circ}$ & $400-850$ & 0.8 & 0.285 & 687 & -270 & 1505 \\
\hline BAM & $\mathrm{H} 4-11$ & OP $-180^{\circ}$ & $400-850$ & 0.8 & 0.323 & 644 & -284 & 1380 \\
\hline BAM & M4-11 & OP-180 & $400-850$ & 0.8 & 0.288 & 729 & -275 & 1422 \\
\hline BAM & K3-11 & OP-180 & $400-850$ & 0.8 & 0.308 & 678 & -279 & 1361 \\
\hline CNR & B31 & OP-180 & $400-850$ & 0.9 & 0.3 & 769 & -289 & 1065 \\
\hline BAM & X2-22 & OP $-180^{\circ}$ & $400-850$ & 1.0 & - & 732 & -274 & 546 \\
\hline CNR & B15 & OP $-180^{\circ}$ & $400-850$ & 1.2 & 0.525 & 854 & -411 & 320 \\
\hline BAM & X2-18 & OP-180 & $400-850$ & 1.4 & - & 870 & -418 & 221 \\
\hline BAM & $\bar{A}$ & Isotherma & 850 & 1.0 & 0.671 & 245 & -261 & 378 \\
\hline BAM & $B$ & Isotherma & 400 & 1.0 & 0.178 & 744 & -722 & 5793 \\
\hline BAM & $C$ & Isotherma & 850 & 1.2 & 0.856 & 244 & -260 & 197 \\
\hline BAM & $\mathrm{D}$ & Isotherma & 400 & 1.2 & 0.342 & 769 & -801 & 2449 \\
\hline
\end{tabular}

Table 1: TMF results of Nimonic 90 alloy

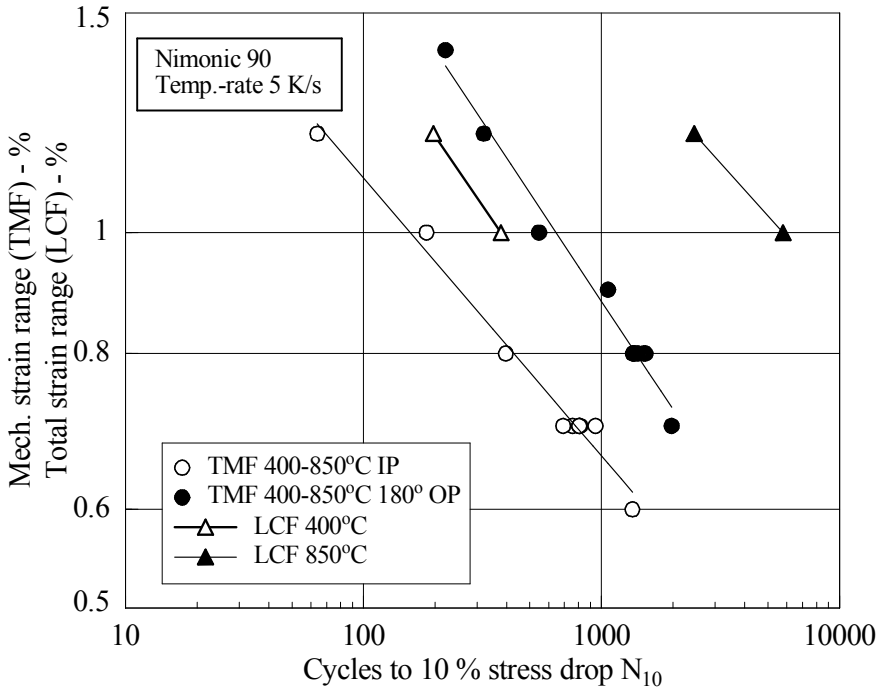

Figure 3: TMF and LCF life of Nimonic 90 alloy
In Fig. 3 the TMF life curves show that the IP condition reduces significantly the fatigue life. The reduction of TMF life for IP cycle could be ascribed to the tensile strain at the maximum temperature that is more damaging than in the $180^{\circ} \mathrm{OP}$ where at maximum temperature there is a compressive stress. The reason for that shall be shown in fractography investigations. The TMF tests have been conducted in both laboratories and they present a very low scatter. The slope of the curve for OP tests is found higher than the IP test curve. Four isothermal LCF tests have been performed at the lowest and the highest temperature used within the TMF tests for comparison. The isothermal LCF tests at $850^{\circ} \mathrm{C}$ show a fatigue life between IP and $180^{\circ}$ OP curves. Whereas the isothermal $400^{\circ} \mathrm{C}$ tests lead to much longer fatigue life than the $180^{\circ} \mathrm{OP}$ tests. 


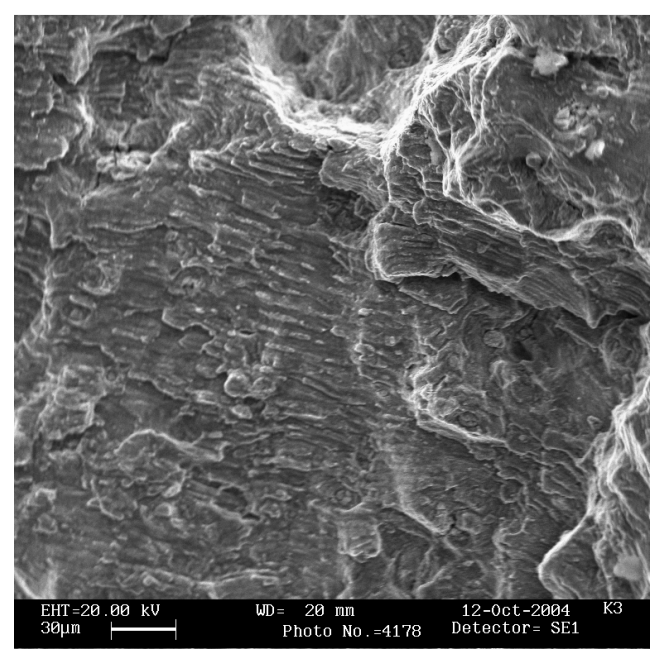

Figure 4: $180^{\circ} \mathrm{OP}$ test; transgranular crack growth, fatigue striations

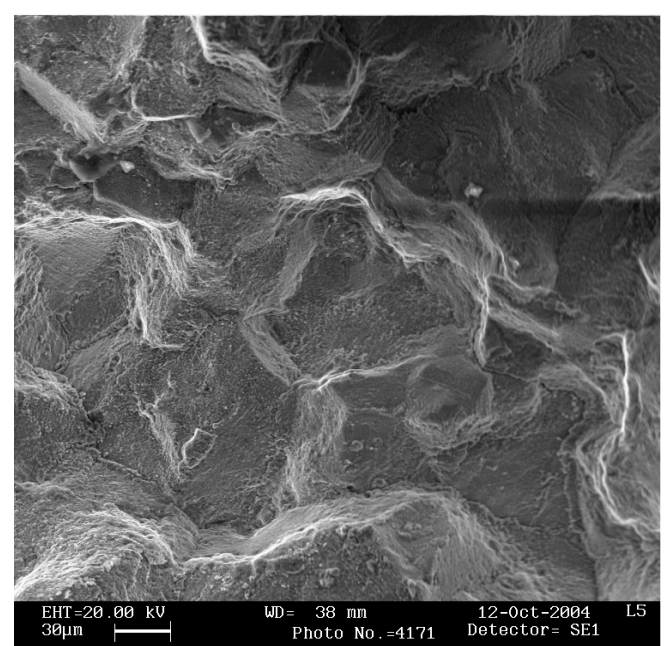

Figure 5: IP test; intergranular crack growth

Some of the fractured specimens have been investigated in order to evaluate the fatigue damage. In general cracks are initiated on the specimen surface and propagate towards the internal in the transgranular mode. OP tests with $\Delta \varepsilon_{\mathrm{m}}=0.8$ $\%$ show multiple crack initiations. In the transgranular crack propagation area few crack striations can be observed (Fig. 4). Figure 5 shows the intergranular crack propagation zone of an IP test with $0.7 \%$ mechanical strain. The grain structure can be clearly seen. The high temperature in the tension phase of the IP test is damaging the grain boundaries more then when it is applied in the compression phase like at OP tests.

\section{Conclusions}

Thermo-mechanical fatigue tests have been conducted in two different laboratories on the Nimonic 90 Nickel-base superalloy. In phase and $180^{\circ}$ out of phase tests have been applied in the temperature range of $400-850^{\circ} \mathrm{C}$ with a temperature rate of $5 \mathrm{~K} / \mathrm{s}$. It was found that the TMF test results of both laboratories can be compared very well. The use of the European Code of Practice is a good tool to improve the comparability of test results obtained in different laboratories. The IP life time was the most detrimental which was due to the change of the fracture mode from transgranular to intergranular which was obtained in fractography investigations. A comparison of TMF and LCF tests complete the reflections. The most detrimental TMF IP test has reached a similar fatigue life compared to an isothermal LCF test at the highest temperature used in the TMF test.

\section{References}

1. Hopkins S.W., Low Cycle Thermal Fatigue of Materials and Components, ASTM STP 612, edited by Spera and Mowbray, ASTM (1976), p. 157

2. J.L. Malpertu and L. Rémy, Low Cycle Fatigue, ASTM STP 942, edited by Solomon et al., ASTM (1988), p. 657

3. H.J. Shi, C. Robin and G. Plevinage, Advances in Fatigue Lifetime Predictive Techniques, Vol. II, ASTM STP 1211, edited by Mitchell and Landgraf, ASTM (1993), p. 105

4. H. Sehitoglu, Fatigue Lifetime Predictive Techniques, ASTM STP 1122, edited by Mitchell and Landgraf, ASTM (1992), p. 47

5. H.L. Bernstain et al., Prediction of Thermal - Mechanical Fatigue Life for Gas Turbines in Electric Power Generation, ASTM STP 1186, edited by Sehitoglu, ASTM (1993), p. 212

6. EU-Project "Thermo-Mechanical Fatigue - The Route to Standardisation", Contract-no G5RDCT-2001-00526, Project-no GRD2-2000.30014, 2001-2005

7. P. Hähner, E. Affeldt, T. Beck, H. Klingelhöffer, M. Loveday, C. Rinaldi, Validated Code of Practice for Thermo-Mechanical Fatigue Testing, European Communities, 2006, ISBN 92-7902216-4 